\title{
KEYAKINAN PERILAKU DAN SIKAP TERHADAP VCT PADA LSL DI SUKOHARJO
}

\author{
Cahyo Nugroho ${ }^{1}$, Tanjung Anitasari Indah Kusumaningrum² \\ ${ }^{1,2}$ Program Studi Kesehatan Masyarakat Universitas Muhammadiyah Surakarta \\ Jl. Ahmad Yani, Kartasura, Surakarta 57162, Jawa Tengah, Indonesia \\ Email: ${ }^{1}$ slicahyo@gmail.com²tanjung.anitasari@ums.ac.id
}

Tanggal Submisi: 26 November 2018; Tanggal Penerimaan: 31 Januari 2019

\begin{abstract}
ABSTRAK
Pada tahun 2017 LSL merupakan kelompok risiko HIV tertinggi di Kabupaten Sukoharjo. VCT merupakan salah satu upaya pencegahan dan penanggulangan HIV/AIDS. Penelitian ini bertujuan untuk mendeskripsikan keyakinan perilaku, dan sikap pada pemanfaatan Klinik VCT pada LSL di Sukoharjo. Jenis penelitian ini merupakan penelitian kualitatif dengan pendekatan studi kasus. Teknik pengumpulan data dengan cara wawancara mendalam kepada lima LSL yang pernah melakukan VCT dan dua informan triangulasi terdiri dari satu PE (Peer Educator) dan satu KL (Koordinator Lapangan) yang diambil dengan purposive sampling. Hasil penelitian menunjukkan bahwa seluruh LSL sudah pernah melakukan VCT namun hanya 4 LSL yang melakukannya secara rutin. Faktor-faktor yang mempengaruhi LSL dalam melakukan VCT secara rutin setiap 3 bulan adalah keyakinan perilaku dan sikap. Namun faktor yang mendasari dalam melakukan VCT adalah keyakinan perilaku bahwa VCT memiliki keuntungan yang lebih banyak jika dibandingkan dengan kerugiannya. Sehingga peneliti menyarankan kepada petugas penanggulangan HIV/AIDS untuk meningkatkan jangkauan kepada LSL yang masih hidden agar VCT secara rutin setiap 3 bulan sekali.
\end{abstract}

Kata kunci : HIV/AIDS, LSL, VCT

ISSN 1979-7621 (Print). ISSN 2620-7761 (Online).

\begin{abstract}
VCT is the entrance to the entire health service of HIV/AIDS. In the year 2017 LSL is the highest HIV risk group in Sukoharjo. This study aims to describe the beliefs of behaviour, and attitudes of VCT in LSL in Sukoharjo. This type of research was qualitative research with approach case studies. The technique of data collection by means of in-depth interviews to five LSL who have done VCT and two informants triangulation consists of one PE (Peer Educator) and one TOS (Field Coordinator) who have get by purposive sampling. The results showed that all the LSL has been conducting VCT but only 4 LSL who do it routinely. Factors that affect the LSL in conducting VCT regularly every 3 months is belief of the behavior and attitude. But the
\end{abstract}


underlying factor in conducting VCT is belief of the behavior that has more advantages when compared with the losses. So the researchers suggest to outreach the LSL is still hidden in order to do VCT regularly every 3 months.

Keywords: HIV/AIDS, MSM, VCT

\section{PENDAHULUAN}

Kasus baru HIV positif pada tahun 2013 sebanyak 29.037 kasus, dan pada tahun 2014 sebanyak 32.711 kasus. Terjadi peningkatan jumlah kasus baru HIV pada tahun 2016 menjadi 41.250 kasus yang sebelumnya pada tahun 2015 sebanyak 30.935 kasus. Jawa Tengah merupakan provinsi dengan urutan keempat di Indonesia dengan jumlah kasus baru HIV sebanyak 4.032 kasus setelah Jawa Timur (6.513 kasus), DKI Jakarta (6.019 kasus), dan Jawa Barat (5.466 kasus) (Kementerian Kesehatan RI, 2016).

LSL merupakan perilaku seksual lakilaki yang berhubungan seks dengan laki-laki, terlepas dari apa yang menjadi motivasi untuk melakukan hubungan seks (Friedman dkk, 2006). Berdasarkan Surveilans Terpadu Biologis dan Perilaku (STBP) tahun 2011 LSL merupakan urutan ke empat dengan prevalensi kasus sebesar $8 \%$ setelah Penasun (36\%), Waria (22\%), dan WPSL (10\%). Prevalensi LSL tersebut meningkat dibandingkan dengan STBP tahun 2007 yaitu prevalensi LSL sebesar 3\%. Menurut UNAIDS The Gap Report (2014) kejadian HIV menurun di sebagian besar dunia namun insiden HIV pada LSL meningkat di beberapa belahan dunia termasuk di Asia. LSL merupakan faktor risiko penularan HIV tertinggi kedua $(21 \%)$ setelah heteroseksual (22\%) dari bulan Oktober sampai dengan Desember 2017 (Kemenkes, 2018).

Menurut Komisi Penanggulangan AIDS (2015) kasus kumulatif HIV dan AIDS di Kabupaten Sukoharjo sebesar 76 kasus. Terjadi peningkatan kasus baru HIV dari 27 kasus pada tahun 2014 menjadi 62 kasus pada tahun 2015 (DKK Sukoharjo, 2015). Berdasarkan Komisi Penanggulangan AIDS Sukoharjo (2017) terdapat 84 kasus HIV dari Januari sampai Oktober 2017 dengan faktor risiko HIV tertinggi yaitu LSL sebesar $30,95 \%$.

VCT merupakan pintu masuk untuk mengetahui status HIV seseorang (Alemie dan Balcha, 2012). VCT juga merupakan upaya untuk melakukan pencegahan penularan HIV (Kemenkes, 2005). Menurut SPEKHAM (2017) hanya terdapat 54 LSL yang VCT dari 1553 LSL di VCT pada tahun 2014 dan terdapat 141 LSL yang VCT dari 1554 LSL pada tahun 2015. Berdasarkan survei pendahuluan yang dilakukan pada bulan November tahun 2017 dari 4 LSL diketahui bahwa semua LSL mengetahui tentang HIV dan fasilitas VCT akan tetapi hanya 2 LSL yang mengaksesnya. Dua LSL lainnya tidak memanfaatkan fasilitas VCT dengan alasan 1 LSL merasa takut jarum suntik dan 1 LSL lainnya merasa takut akan stigma dan kurang terjaminnya kerahasiaan klien.

Berdasarkan Theory of Reasoned Action, seseorang melakukan tindakan dipengaruhi oleh sikap seseorang yang mana sikap seseorang juga ditentukan oleh keyakinan seseorang terhadap perilaku yang akan dilakukan. Sama halnya dengan perilaku VCT pada LSL, LSL akan melakukan VCT dipengaruhi oleh sikap LSL terhadap VCT tersebut. Sikap LSL terhadap VCT juga dipengaruhi oleh keyakinan LSL terhadap VCT. Namun hal ini bertolak belakang dengan hasil penelitian Mujiati \& Pradono (2014) yang menyatakan bahwa 
tidak ada hubungan antara sikap petugas kesehatan dengan pemanfaatan klinik VCT sehingga penelitian ini bertujuan untuk mengetahui gambaran keyakinan perilaku dan sikap LSL terhadap VCT secara mendalam, sehingga dapat mendeskripsikan apakah keyakinan perilaku dan sikap LSL mendasari atau melatarbelakangi LSL untuk melakukan VCT secara rutin atau tidak.

\section{METODE PENELITIAN}

Jenis penelitian ini adalah penelitian kualitatif. Penelitian ini menggunakan pendekatan studi kasus dengan kasus dalam penelitian ini yaitu pemanfaatan VCT oleh LSL di Sukoharjo. Subjek penelitian ini terdiri dari 5 informan utama dan 2 informan triangulasi. Informan utama terdiri dari lima LSL yang pernah VCT. Cara penentuan informan utama menggunakan purposive sampling dengan kriteria LSL di Sukoharjo yang pernah VCT, dan informan triangulasi adalah peer educator dan coordinator lapangan. Analisis data pada penelitian ini menggunakan content analysis.

\section{HASIL DAN PEMBAHASAN}

\section{Karakteristik Informan}

Informan utama dalam penelitian ini berjumlah 5 orang LSL yang ada di Wilayah Kabupaten Sukoharjo yang bersedia berpartisipasi sebagai informan penelitian dengan pengambilan sampel berdasarkan snowball sampling. Sebagian besar informan utama berpendidikan SMA dan satu informan utama berpendidikan S1. Rata-rata informan utama berusia produktif dan terdapat dua informan utama berusia lebih dari 49 tahun. Sedangkan informan triangulasi terdiri dari 2 informan dengan 1 informan utama berpendidikan SMA dan 1 informan lainnya berpendidikan S2. Informan triangulasi memiliki pekerjaan sebagai peer educator dan koordinator lapangan.

\section{Keyakinan Perilaku}

Seluruh LSL memiliki keyakinan bahwa VCT memiliki keuntungan yang lebih banyak jika dibandingkan dengan kerugiannya. Informan dalam penelitian ini mengungkapkan bahwa VCT memiliki keuntungan untuk mengetahui status HIV sejak dini. Apabila VCT dilakukan secara rutin maka seseorang akan mengetahui status HIV sejak dini sehingga dapat mencegah sampai ke tahap AIDS karena VCT juga merupakan layanan yang menghubungan dengan layanan CST atau Care, Support and Treatment. Sebagian besar informan dalam penelitian ini juga mengungkapkan bahwa melakukan VCT tidak ada kerugiannya.

"Dapat diketahui status HIV sedini mungkin. Kalau diketahui sejak awal pasti belum parah, kalau diketahui saat sudah parah bisa saja tidak tertolong. Sebenarnya melakukan VCT tidak ada kerugiannya" (IU4)

Namun berbeda dengan pendapat informan yang lain, salah satu informan dalam penelitian ini mengungkapkan bahwa kerugian dalam melakukan VCT adalah mendapatkan stigma dari lingkungan yaitu dari pengunjung puskesmas yang lain. Pernyataan tersebut juga diungkapkan oleh informan triangulasi bahwa LSL dalam melakukan akses ke layanan VCT terkadang mendapatkan stigma dari lingkungan sekitar bahwa mereka adalah orang yang berperilaku tidak baik dan lekat dengan norma negatif masyarakat.

"LSL saat VCT mendapatkan stigma oleh masyarakat dan beberapa layanan VCT. Itu yang menjadi kerugian. Apalagi kalau ada LSL yang meninggal pasti distigma kalau terkena HIV padahal belum tentu” (IU3)

Maulida (2018) menyatakan bahwa stigma terhadap kelompok risiko LSL memiliki hubungan dengan keikutsertaan VCT. Informan triangulasi mengungkapkan bahwa stigma maupun diskriminasi dari lingkungan sekitar dapat dihilangkan dengan cara pemberian edukasi mengenai HIV/AIDS dan VCT. Edukasi tentang HIV/AIDS dapat berisi informasi bahwa HIV/AIDS itu yang perlu dijauhi adalah virusnya dan bukan 
ODHA-nya (Orang dengan HIV/AIDS). Hal ini sesuai dengan Dirjen P2PL Kemenkes RI (2012) stigma masyarakat dapat secara perlahan memudar dengan dilakukan sosialisasi tentang HIV/AIDS dan VCT dengan penjelasan sudut pandang mengenai keadilan sosial yaitu pemanfaatan layanan kesehatan bagi populasi berisiko.

LSL dalam penelitian ini juga mengungkapkan bahwa antara keuntungan dalam melakukan VCT dan kerugian dalam melakukan VCT masih tetap lebih banyak atau lebih berat keuntungannya dalam melakukan VCT. Informan juga menyatakan bahwa setelah mempertimbangkan antara keuntungan dan kerugian dalam melakukan VCT seluruh informan menyatakan mau untuk melakukan VCT secara rutin.

"Mau karena untuk terus menjaga kesehatan dan kondisi kesehatan apakah terkena HIV atau tidak" (IU5)

Hanya saja terdapat salah satu informan yang menyatakan walaupun mau melakukan VCT namun informan tetap akan melakukan VCT disaat mentalnya sudah siap untuk melakukan dan menerima hasil VCT.

\section{Sikap}

Sikap (Attitude) adalah perasaan positif/negatif jika seseorang harus melakukan perilaku. Sikap dipengaruhi oleh behavior beliefs yaitu kekuatan kepercayaan dan evaluasi terhadap hasil yang dihubungkan dengan perilaku. Tiga LSL memiliki sikap bahwa HIV merupakan penyakit yang berbahaya dan mematikan. Dua LSL memiliki sikap bahwa HIV bukanlah penyakit yang menakutkan.

"HIV merupakan penyakit yang mematikan, menjadi momok karena penyakit tersebut menyerang daya tahan tubuh" (IU2)

Seluruh LSL dalam penelitian ini memiliki sikap bahwa VCT merupakan suatu proses yang sangat bagus dan bermanfaat untuk mengetahui status HIV. VCT merupakan proses yang harus dilakukan oleh semua orang tidak hanya yang berisiko tinggi namun juga orang-orang yang merasa dirinya berisiko bahkan bagi orang yang berisiko rendah sekalipun.

"VCT harus tetap dilakukan kepada setiap orang yang berisiko, bahkan orang-orang yang heteroseksual jika bergonta-ganti pasangan termasuk berisiko juga jadi harus VCT karena VCT dapat mengetahui status HIV" (IU5)

Pernyataan informan utama ini juga sejalan dengan pernyataan informan triangulasi yang menyatakan bahwa VCT adalah suatu tes untuk mengetahui status HIV seseorang yang didasari rasa sukarela untuk melakukannya. VCT baik dilakukan untuk semua orang tidak hanya kelompok berisiko tinggi seperti LSL, WPSL maupun WPSTL. Namun juga untuk kelompok risiko rendah seperti pelajar, petugas medis ataupun guru dan warga sipil biasa lainnya. Seluruh LSL memiliki sikap bahwa mereka mau untuk melakukan VCT secara rutin. Satu dari LSL tersebut menyatakan walaupun informan mau untuk melakukan VCT secara rutin namun tetap akan melakukan VCT apabila mentalnya telah siap. Oleh karena itu perlu dorongan yang lebih dari pasangan dan teman agar informan merasa memiliki mental yang siap untuk melakukan VCT secara rutin. Pendapat informan tersebut serupa dengan penelitian Fatmala (2016) yang menyatakan bahwa hambatan VCT sebagian besar berasal dari ketakutan akan hasil VCT dan LSL juga takut jika banyak orang yang akan mengetahui hasil tes VCT-nya.

\section{KESIMPULAN}

Keyakinan perilaku LSL dalam pemanfaatan klinik VCT yaitu seluruh LSL memiliki persepsi bahwa apabila melakukan VCT akan mendapatkan keuntungan. VCT memiliki keuntungan untuk mengetahui status HIV sejak dini apabila VCT dilakukan secara rutin maka akan bermanfaat untuk mengetahui apakah seseorang terkena HIV/AIDS atau tidak sehingga dapat 
dilakukan upaya pencegahan dan HIV. Empat LSL sudah melakukan VCT penanggulangan HIV/AIDS sedini mungkin. secara rutin Sedangkan 1 LSL menyatakan Sikap LSL dalam pemanfaatan klinik VCT mau melakukan VCT secara rutin apabila yaitu LSL memiliki sikap yang baik dalam melakukan VCT karena LSL sudah pernah melakukan VCT dan LSL beranggapan bahwa VCT berguna untuk mengetahui status

\section{DAFTAR PUSTAKA}

Alemie \& Balcha. (2012). VCT Clinic, HIV Burden and its Link with HIV Care Clinic at The University Of Gondar Hospital. Journal of BMC Public Health, Vol. 12.

David S.G. (1997). Handbook of Health Behavior Research. New York: Plenum Press,

Dirjen P2PL Kemenkes RI. (2012). Buku Pedoman Penghapusan Stigma \& Diskriminasi Bagi Pengelola Program, Petugas Layanan Kesehatan dan Kader.

Fatmala. (2016). Faktor Predisposing, Enabling, dan Reinforcing dalam Pemanfaatan VCT oleh Laki-Laki Seks dengan Laki-Laki (LSL). Jurnal Berkala Epidemiologi, 4(1):138-150

Friedman, H. S \& Schustack, M. W. (2006). Kepribadian Teori Klasik dan Riset Modern Edisi Ketiga. Jakarta: Erlangga

Heri D.J.M. (2009). Promosi Kesehatan. Jakarta: Penerbit Buku Kedokteran EGC

Kementerian Kesehatan RI. (2005). Keputusan Menteri Kesehatan Republik Indonesia Nomor 1507/MENKES/SK/X/2005 Tentang Pedoman Pelayanan Konseling dan Testing HIV/AIDS Secara Sukarela (Voluntary Counseling and Testing). Jakarta: Kementerian Kesehatan Republik Indonesia.

Kementerian Kesehatan RI. (2016). Profil Kesehatan Indonesia Tahun 2016. Jakarta: Kementerian Kesehatan Republik Indonesia.

Kementerian Kesehatan RI. (2018). Laporan Perkembangan HIV-AIDS \& Infeksi Menular Seksual (IMS) Triwulan IV Tahun 2017. Jakarta: Kementerian Kesehatan Republik Indonesia

Komisi Penanggulangan AIDS Kabupaten Sukoharjo. (2017). Data Penemuan Kasus Baru HIV Bulan Januari-Oktober Tahun 2017. Sukoharjo: Komisi Penanggulangan AIDS Kabupaten Sukoharjo.

Komisi Penanggulangan AIDS Provinsi Jawa Tengah. (2015). Strategi dan Rencana Aksi Daerah Penanggulangan HIV dan AIDS. Semarang: Komisi Penanggulangan AIDS Provinsi Jawa Tengah.

Maulida, M. R. (2018). Hubungan Penjangkauan Dan Stigma Dengan Keikutsertaan VCT Pada Kelompok Risiko LSL. Jurnal Ilmiah Permas Jurnal STIKES Kendal Volume 8 No 1, Hal 6-12, April 2018. Kendal: Sekolah Tinggi Ilmu Kesehatan Kendal.

Mujiati \& Pradono. (2014). Faktor Persepsi dan Sikap dalam Pemanfaatan Layanan Voluntary Counseling and Testing (VCT) oleh Kelompok Berisiko HIV/AIDS di Kota Bandung Tahun 2013. Jurnal Kesehatan Reproduksi, 5(1), 49-57

SPEKHAM. (2017). Data Jumlah VCT LSL Tahun 2014 dan 2015. Sukoharjo: LSM. Solidaritas Perempuan Untuk Kemanusiaan dan Hak Asasi Manusia.

Surveilans Terpadu Biologis dan Perilaku. (2007). Surveilans Terpadu Biologis dan Perilaku Pada Kelompok Berisiko Tinggi di Indonesia. Jakarta: STBP.

Surveilans Terpadu Biologis dan Perilaku. (2011). Surveilans Terpadu Biologis dan Perilaku Pada Kelompok Berisiko Tinggi di Indonesia: Lembar Fakta Ringkasan Eksekutif. Jakarta: STBP. 